\title{
The Development of Stereotypes About the Rich and Poor: Age, Race, and Family Income Differences in Beliefs
}

\author{
Taniesha A. Woods, ${ }^{1}$ Beth Kurtz-Costes, ${ }^{2}$ and Stephanie J. Rowley ${ }^{3}$
}

Received June 2, 2004; revised October 7, 2004; accepted October 25, 2004

African American and European American 4th, 6th, and 8th graders rated the competence of rich and poor children in academics (i.e., math, science, reading, writing, school grades, smartness), sports, and music. In contrast to middle school students, 4 th graders favored the rich in all 3 domains. Youth of both races reported that the rich were more competent in academics than the poor; these beliefs were especially pronounced among Black youth. White, older, and more affluent students favored the poor in sports, whereas their counterparts either favored the rich or were egalitarian. No interactions were found between grade and race or grade and family income. The implications of these beliefs for policy and identity development theory are discussed.

KEY WORDS: stereotype development; social class; achievement related beliefs; education policy; identity development.

Stereotypes are generalized judgments about an individual, based on his/her membership in a particular social group (cf. Ruble et al., 1984). Images in the popular media as well as results of research indicate that many Americans hold negative stereotypes about poor people. The purposes of the present investigation were to learn whether young adolescents believe that rich and poor children differ in academic, sports, and music abilities, and to examine whether these beliefs differ across age, race, and family income groups. The first section of this paper explicates why these beliefs are important to study. Next, developmental, race, and income differences in beliefs are discussed. We conclude with a summary of the project goals.

\footnotetext{
${ }^{1}$ Doctoral student at the University of North Carolina, Chapel Hill. Research interests include the influence of race identity, race socialization, and stereotypes on the academic achievement of African American youth. To whom correspondence should be addressed at Department of Psychology, CB \#3270, University of North Carolina, Chapel Hill, North Carolina 27599-3270; e-mail: taniesha@ email.unc.edu; bkcostes@email.unc.edu.

${ }^{2}$ Associate Professor at the University of North Carolina, Chapel Hill. Received Ph.D. in Psychology at the University of Notre Dame. Her research specialty is the development of children's achievement-related beliefs.

${ }^{3}$ Assistant Professor at the University of Michigan. Received Ph.D. from the University of Virginia. Research interests include predictors of academic self-views in children and adolescents.
}

\section{POVERTY, BELIEFS, AND SOCIAL POLICY IN THE UNITED STATES}

In 2003, a little over 12 million or approximately 1 in 6 children lived in poverty in the United States (U.S. Census Bureau, American Community Survey of the United States, 2003). In spite of the prevalence of poverty in our country and of the devastating nature of severe economic need, little research has examined children's beliefs about the abilities of rich and poor children (cf. Chafel, 1995; Lott, 2002). The general population as well as psychological researchers often distance themselves from poor individuals (Lott, 2002). Most middle and upper class individuals have never experienced severe and enduring financial hardship, and therefore are unsympathetic to the plight of indigent people (Chafel, 1997; Leahy, 1983; Lott, 2002). Attitudes of disregard and avoidance of the poor are often implicitly and explicitly conveyed to children.

A growing body of research has now shown that stereotypes are powerful and can negatively influence the performance of members of the stereotyped group - even when those individuals do not, themselves, endorse the stereotypes (e.g., Aronson, 2002; Croizet et al., 2001; Snyder and Stukas, 1999; Steele, 1997). This body of research has shown that priming poor or working class participants to be aware of their socioeconomic status 
(or that priming membership in other negatively stereotyped groups for those group members) leads to underperformance on cognitive tasks.

Stereotypes also influence the behavior of those individuals who hold the stereotypes. Beliefs about the characteristics of poor people and the causes of poverty undoubtedly influence, directly and indirectly, middle class voting behavior, social policy decisions, beliefs about welfare, and willingness as a society to end poverty (cf. Cozzarelli et al., 2001). Chafel (1997) and others have argued that enduring negative societal images of the poor have contributed to the prevalence and persistence of poverty in this country. The poor are either overlooked by the popular media or are portrayed as deficient and morally bankrupt (Bullock et al., 2001). These images permit a "blame the victim" mentality passed down to children with each generation that is used to justify social policy that disenfranchises a significant proportion of our population and has created a seemingly permanent welfare class (Chafel, 1997). Thus, one reason to study adolescents' beliefs about the rich and poor is to obtain descriptive data about the formation of early beliefs. A second reason that research in this area is important is because of its implications for identity development.

\section{THE DEVELOPMENT OF STEREOTYPES ABOUT THE RICH AND POOR}

Because the poor are often portrayed as ignorant, lazy, dishonest, and disinterested in self-improvement (Bullock, 1995, 1999; Cozzarelli et al., 2001), it is likely that children in the United States come to think about and understand individuals from low socioeconomic backgrounds negatively. The negative messages about poor individuals that are implicitly and explicitly transmitted to children and adolescents could affect the way in which they view themselves, with negative repercussions for youth from disadvantaged backgrounds. As Weinger (1998) poignantly describes from her interviews with poor children, even 5-year olds are aware of the wealth disparities in our country and of societal messages that are disparaging of the poor. Research in gender has shown the potential role that stereotypes may play in identity development (e.g., Bornholt et al., 1994; Tiedemann, 2000). Stereotypes may be especially important during the transition to adolescence, when youths are experiencing rapid change socially, cognitively, and physically.

A cognitive developmental perspective suggests that stereotypes influence information processing by determining how information is encoded and interpreted, thereby affecting the beliefs that individuals hold about themselves and others (Bigler and Liben, 1992; Hamilton et al., 1994). For example, individuals who believe that poor children are poor students might be more likely to remember instances of school failure in children from economically struggling families than children from affluent families, and will be more likely to attribute the former failures to the children's lack of ability rather than situational factors such as lack of effort. Although children's and adolescents' developing awareness of group differences has been studied extensively in the domain of gender, and to a lesser extent race (e.g., Bigler and Liben, 1992, 1993), to date relatively little research has examined the development of stereotypes about the rich and poor. The relationship between social class stereotypes and identity development may be complicated by the fact that social class, unlike race and gender, is often not physically apparent.

In an early study of children's understanding of wealth and poverty, Stendler (1949) found age-related differences in 1st, 4th, 6th, and 8th graders' conceptions of the poor. Younger children made few distinctions other than to recognize that "rich" was desirable and "poor" was undesirable. The oldest children in Stendler's sample recognized that desirable or undesirable behavior can be shown by either the rich or the poor. In a more recent, large-scale study of adolescents aged 11-16, Skafte (1988) found that wealthy individuals were rated as more intelligent, making better grades, and making friends more easily than poor individuals. Reports did not vary by age. In her 1995 review, Chafel concluded that although wide variations in research methodologies probably explain inconsistencies in results and make it difficult to generalize across the relatively few research studies in this area, the results are consistent in one regard: With age, children's ideas become more differentiated and complex.

In addition to our focus on age differences across the transition to adolescence, we examined race and family income differences in beliefs. Particularly for youth entering adolescence who are becoming aware of the social stratification and financial and power inequities in society, life experiences that are correlated with race and social class membership probably lead to some differences in beliefs. This topic is explored next.

\section{RACE AND INCOME DIFFERENCES IN SOCIAL CLASS STEREOTYPES}

Individuals tend to show a bias in favor of the social groups to which they belong, and both adults and children form in-group biases quickly and easily (Bigler 
et al., 2001; Crocker and Major, 1989; Tajfel and Billig, 1974). However, when groups differ in status, low-status groups-in contrast to high-status groups-do not necessarily show an in-group bias (Bigler et al., 2001; Tajfel, 1970). In Bigler et al.'s (2001) experimental manipulation with children in a summer camp, low-status groups were likely to hold neutral beliefs in domains in which their group had been negatively stereotyped, in contrast to high-status groups, who held positive beliefs about ingroup members.

From the perspective of self-enhancement theory or in-group bias, middle- and upper-income individuals would be expected to favor the rich in their rankings, whereas lower income adolescents would rate the poor more favorably. Consistent with this view, upper middle class individuals are more likely than less affluent individuals to claim that poverty cannot be changed and is the result of wasting money (Bullock, 1999; Leahy, 1983). However, an alternative hypothesis posits that children and adolescents from lower class backgrounds are more aware than their affluent peers of the limited life chances afforded by poverty, and therefore are more likely to note these limited chances in evaluating others (Leahy, 1981; Weinger, 1998). In the current project, we tested these contrasting hypotheses about the relationship between family income and adolescents' beliefs.

We also tested for race differences in beliefs. Because a disproportionate number of racial and ethnic minority group members are poor, members of ethnic minority groups - even those who are not poor themselves-may hold more positive views of poor individuals than do European Americans (cf. Hunt, 1996). In his study of children and adolescents, Leahy (1983) found that Black students were less likely than Whites to state that poverty was the result of either bad luck or the fault of the individual. African Americans in the sample viewed poverty more as a social condition that has structural/societal origins, whereas European Americans indicated that poverty was individually caused, inherent to some segments of the population, and could not be changed. Just as these youth held diverging views of the causes and consequences of poverty, young adolescents may also show race differences in their beliefs about the abilities of rich and poor children.

\section{SOCIAL CLASS STEREOTYPES ABOUT ACADEMIC, SPORTS, AND MUSIC ABILITIES: THE CURRENT PROJECT}

Most research to date that has examined beliefs about and attitudes toward poor individuals has focused either on the causes of poverty or personal descriptors (e.g., clean, uneducated, hardworking, humble) (Bullock, 1999; Cozzarelli et al., 2001). Little research has examined beliefs about academic abilities, in spite of the importance of academic success for social mobility in our country, and in spite of negative stereotypes about the intellectual/academic abilities of the poor (Croizet et al., 2001; Lott, 2002). In addition to the focus on academic skills, we asked young adolescents about the musical and sports abilities of the rich and poor. We selected these areas of competency because they are highly salient to children in late childhood and early adolescence. As children enter middle school with its increasing emphasis on achievement outcomes, youths are cognizant of individual differences in these 3 areas, and much of their time use and social choices are shaped by the relative emphasis they place on these 3 types of activities (Freedman-Doan et al., 2000). In addition, we hypothesized that sports and music are 2 domains in which the poor might not be negatively stereotyped. As the popular media often portray, the sports and music professions include individuals who grew up poor (e.g., Jesse Owens, Maury Wills, Jackie Joyner-Kersey, Sammy Sosa, Jim Thorpe, Jewel).

In the current study, we measured adolescents' stereotypes about wealth-related differences in academic, music, and sports skills, and determined whether these beliefs varied as a function of age, race, and family income. We hypothesized increasing complexity in beliefs with age (cf. Chafel, 1995), anticipating that younger students would view the rich as more competent in all domains, whereas older students would hold more differentiated views. A prevalent social class stereotype in our society is that the poor are less intelligent than the rich (Bullock, 1995, 1999; Cozzarelli et al., 2001). It is less clear that society conveys consistent messages about social class differences in sports and music. Given some popular media emphases, older youths were expected to report either egalitarian sports and music beliefs, or that the poor were more competent.

As described above, 2 competing hypotheses led to different predictions regarding the relationship between family income and beliefs. If adolescents' responses reflect an in-group bias, middle and upper income students would favor the rich, and lower income students would favor the poor. In contrast, if these beliefs are shaped to a large extent by personal experience, low-income students might rank the poor more negatively because of their awareness of the extent to which economic hardship thwarts the development of excellence in sports and music. Race differences in beliefs were examined in an exploratory fashion. 


\section{METHOD}

\section{Participants}

Participants for this study came from the larger Children's Beliefs about Stereotypes project. The full sample for the data presented here consisted of 438 African American and European American students (182 boys, 256 girls) from 10 schools in 1 urban and 1 rural school district in North Carolina. Two hundred and thirty-four students were African American and 204 were European American. The sample included 1534 th $(M=9.6$ years, $S D=.73), 1356$ th $(M=11.5$ years, $S D=.68)$, and 150 8 th grade students $(M=13.5$ years, $S D=.57)$. With the exception of 1 school that served children in kindergarten through 8th grade, 4th graders were all in elementary school, and 6th and 8th graders were drawn from middle schools serving grades 6 through 8 . Race and gender were approximately evenly distributed across grades. In the 2 school districts in which the research was conducted, 32 and $36.5 \%$ of students received free or reduced lunch.

Some of the analyses reported below were conducted on data from students whose parents completed a parent questionnaire listing their yearly income. Because not all parents completed the questionnaires, the sample was reduced to 172 participants for the analyses with parents' income. Of these 172 children, 69 were in the 4th grade, 48 were in the 6th grade, and 55 were in the 8th grade. Seventy-five were African American, and 97 were European American. Parent educational attainment in these families was as follows: $5 \%$ had less than a high school education; $16 \%$ had obtained a high school diploma; $38 \%$ had attended some college, but did not graduate; $29 \%$ had a 4 -year college degree; $12 \%$ had done some postgraduate work. Parent education and income were evenly distributed across age groups.

\section{Procedure}

Written parental consent was obtained for all child participants. Self-report questionnaires were administered to children in a group setting on school grounds. Children received 1 small gift (e.g., stress ball, key chain, pencil) for returning the consent form and another for participating in the study. Parents who agreed to participate were mailed a questionnaire that they completed at their convenience and then returned by mail. Parents received a 10-dollar gift certificate for returning the questionnaire.

\section{Measures}

We assessed students' beliefs about the competence in various domains of the following social groups: boys, girls, Black, White, rich, and poor. Only data from "rich" and "poor" scales were used for this paper. Competence was rated for academics, sports, and music abilities. Students were asked to make a mark on a $100-\mathrm{mm}$ line to indicate how well they thought each social group did in a particular activity. For example, the item "I think that in sports rich children do this well," was followed by a 100 -mm scale with "not at all good" located at the far left and "very good" located at the far right. Six items referred to academic domains (math, science, reading, writing, school grades, and smartness). These 6 items were averaged to obtain the academic score. Single items represented music and sports. Students completed all 8 items about a social group (e.g., girls) before going on to answer questions about another social group. The protocol was ordered in such a way that 2 counterparts of a social category were never adjacent. For example, boys and girls or rich and poor were not adjacent to each other. Moreover, the sequence of social groups was counter-balanced; thus 3 different protocol sequences were used to eliminate possible effects of response bias.

The distance between the low end of each scale and the respondent's mark was measured in millimeters for each item, yielding a possible range of 0 (not good at all) to 100 (very good) for each competence item score. These scores were used to calculate a difference (stereotype) score subtracting the student's ranking for the poor from the ranking for the rich within each domain (e.g., writing, math, science, etc.). Thus, positive scores indicated that the student favored the rich, scores close to zero represented egalitarian beliefs, and negative scores favored the poor.

\section{Demographics}

Each student reported his/her grade in school, age in years and months, and gender. Students were also asked to indicate which ethnicity/race best described them by circling one of the following labels: White/European American, Black/African American, Hispanic/Latino, Native American, Asian American/Pacific Islander, and Other. Those children who selected "Other" were asked to indicate their ethnicity/race in the space provided. For the present analyses only those students who circled White/European American or Black/African American were included.

Parents reported their yearly family income by selecting 1 annual income range from the following 11 choices: (1) less than $\$ 10,000$, (2) $\$ 10,000$ to $\$ 19,999$, (3) $\$ 20,000$ to $\$ 29,999$, (4) $\$ 30,000$ to $\$ 39,999$, (5) $\$ 40,000$ to $\$ 49,999$, , (6) $\$ 50,000$ to $\$ 59,999$, (7) $\$ 60,000$ to $\$ 69,999$, (8) $\$ 70,000$ to $\$ 79,999$, (9) $\$ 80,000$ to $\$ 89,999$, (10) $\$ 90,000$ to $\$ 99,999$, and (11) greater than $\$ 100,000$ per 
year. For most analyses, income scores were regrouped into 3 categories: a low-income group, a middle-income group, and a high-income group. The low-income group was comprised of 43 families (36 African American and 7 European American) who earned less than $\$ 30,000$ per year. The middle-income group consisted of 65 families (34 African American and 31 European American) who earned $\$ 30,000$ to $\$ 79,999$ per year. The high-income group included 63 families (5 African American and 58 European American) who had a yearly income of $\$ 80,000$ or more.

\section{RESULTS}

To determine if students' stereotype beliefs differed based on age, race, and family income, multivariate analyses of variance (MANOVAs) and univariate analyses of variance (ANOVAs) were performed using the statistical package SPSS 11.5. All multivariate analyses included the 3 dependent variables social class stereotypes for sports, academics, and music. Subsequent univariate analyses examined each stereotype domain separately. As described above, participants were placed in 1 of the 3 groups according to their family income.

\section{Grade and Race Differences in Stereotypes}

We examined possible grade and race differences in stereotypes using MANOVAs on the 3 stereotype scores. These analyses were conducted without entering family income as an independent variable in order to maximize statistical power. This (3)Grade $\times(2)$ Race MANOVA yielded significant main effects of Grade and Race, $F(6,860)=3.6, p<.01$ and $F(3,430)=2.8$, $p<.05$, respectively. The Grade $\times$ Race interaction was nonsignificant. Means are reported in Tables I and II.

The significant multivariate effect for Grade was driven by stereotypes regarding sports and music,

Table I. Mean Differences for Social Class Stereotypes as a Function of Grade

\begin{tabular}{lccc}
\hline \multirow{2}{*}{$\begin{array}{c}\text { Stereotype } \\
\text { domain }\end{array}$} & 4 & 6 & 8 \\
\cline { 2 - 4 } & \multicolumn{4}{c}{ Grade } \\
\hline Sports** $_{\text {Academics }}$ & $8.5^{a}(40.6)$ & $-11.2^{b}(37.0)$ & $-9.5^{b}(38.1)$ \\
Music* & $18.6(33.4)$ & $12.4(28.4)$ & $12.8(25.4)$ \\
$n$ & $13.1^{a}(39.3)$ & $3.4^{b}(35.6)$ & $.2^{b}(32.2)$ \\
\hline
\end{tabular}

Means differ at ${ }^{*} p<.05 ;{ }^{* *} p<.0001$.

Note. Higher positive scores indicate that rich children were judged as more competent than the poor. Negative scores favor the poor. Superscript letters indicate which means differ significantly from each other. Standard deviations are listed in parenthesis.
Table II. Mean Differences for Social Class Stereotypes as a Function of Race

\begin{tabular}{lcc}
\hline & \multicolumn{2}{c}{ Race } \\
\cline { 2 - 3 } \multicolumn{1}{c}{$\begin{array}{c}\text { Stereotype } \\
\text { domain }\end{array}$} & $\begin{array}{c}\text { African } \\
\text { American }\end{array}$ & $\begin{array}{c}\text { European } \\
\text { American }\end{array}$ \\
\hline Sports* $^{*}$ & $1.0(41.5)$ & $-9.1(36.6)$ \\
Academics* & $18.0(32.3)$ & $10.9(25.1)$ \\
Music & $7.8(38.5)$ & $3.3(33.4)$ \\
$n$ & 234 & 204 \\
\hline
\end{tabular}

*Means differ at $p<.05$.

Note. Higher positive scores indicate that rich children were judged as more competent than the poor. Negative scores favor the poor. Standard deviations are listed in parenthesis.

$F(2,432)=8.8, p<.0001$ and $F(2,432)=4.3, p<$ .05 , respectively. In sports, younger students favored the rich, whereas older students held views that favored the poor. Simple contrasts among these means showed that 4th graders' beliefs differed from those of 6th and 8th graders, who did not differ from each other. Cohen's $d$ statistic was used to find effect sizes. Grade differences in sports stereotypes were of moderate magnitude, $d=.47$.

For music, 4th graders held beliefs that favored the rich, 6th graders held stereotypes that slightly favored the rich, whereas 8th graders indicated that there was no difference between the rich and poor in music abilities. Simple contrasts among these means indicated that 4th graders differed from both 6th and 8th graders, who did not differ from each other. Sixth and 8th graders were egalitarian, whereas 4th graders reported that the rich are more competent. An effect size of $d=.31$ indicated that these differences were small in magnitude.

As indicated by the positive means, all 3 age groups favored the rich in academics. Academic stereotypes did not differ across grades.

Univariate ANOVAs on each stereotype score showed that the main effect of Race was driven by sports and academics scores, $F(1,432)=4.7$ and 5.2, respectively, $p$ s $<.05$. White students favored the poor in their sports stereotypes, whereas African American students held egalitarian views. In the domain of academics, all students reported that the affluent are more competent than the poor; however, group differences were greater among Blacks than Whites. The effect size for sports and academic stereotypes were .25 and .24 respectively, indicating relatively small differences between the 2 groups. Beliefs about music ability did not differ by race.

\section{Stereotypes as a Function of Family Income}

In order to determine whether beliefs about the rich and poor differed as a function of family income, a (3)Income $\times(3)$ Grade multivariate analysis of variance was 
conducted on the 3 stereotype scores. Grade was entered in this analysis only to determine if the Income effects differed across Grade levels. The main effects of Income and Grade were significant, $F(6,322)=3.2$ and 3.6, respectively, both $p^{\text {'s }}<.01$. The Income $\times$ Grade interaction was nonsignificant.

Univariate ANOVAs examining the main effect of Income showed significant differences in sports stereotypes, $F(2,163)=3.3, p<.05$. Students from low-income backgrounds $(M=3.6, S D=46.3)$ slightly favored the rich or were egalitarian, while students from middle-income backgrounds $(M=-5.2, S D=42.8)$ held views that favored the poor, and students from high-income backgrounds $(M=-19.3, S D=35.0)$ reported that poor children are much better at sports than are rich children. Simple contrasts among the means showed that low-income students' beliefs differed significantly from the beliefs of high-income students, while middle-income students did not differ from the other 2 groups. Univariate ANOVAs examining academic and music stereotypes were nonsignificant. The main effect of Grade was not examined further, as these analyses were conducted with the whole sample.

Because of the disproportionate numbers of highincome European Americans and low-income African Americans in our sample, we wanted to further examine the relationships among race, family income, and sports stereotypes to determine whether the race differences in sports stereotypes reported above were driven primarily by race or by family income. A (2)Race $\times$ (3)Income MANOVA was not conducted because there were too few high-income African American families and too few lowincome European American families in the sample. Instead, regression analyses were conducted using sports stereotypes as the dependent variable, and race and family income as the predictor variables. For this analysis, the full scale of income (i.e., 11 values ranging from an annual income of less than $\$ 10,000$ to an annual income of greater than $\$ 100,000)$ was used rather than the recoded variable. The equation was significant, $F(2,169)=4.58$, $p=.012$. Family income was a significant predictor of beliefs about sports abilities, $\beta=-.19, t(169)=2.04$, $p=.04$. Race was nonsignificant, $t(169)<1.0$.

\section{DISCUSSION}

Millions of children in the United States are living in poverty, and the ratio of economic earnings between the poorest $20 \%$ and wealthiest $1 \%$ in our country has changed from approximately $1: 21$ to approximately $1: 63$ in the past 20 years (Shapiro et al., 2001 as cited in Lott, 2002). Public policy decisions that have enabled these income disparities are shaped by mainstream American attitudes and beliefs that view poverty as primarily the result of individual characteristics (laziness, lack of intelligence, lack of ambition) rather than structural/institutional factors (Bullock, 1999; Lott, 2002). In this project, we examined age, race, and family income differences in the beliefs of children and young adolescents regarding academic, music, and sports abilities of the rich and poor. Consistent with social stereotypes in our country, the poor were reported to be less competent academically than the rich by all age groups in our sample. In addition, beliefs differed by age, race, and family income. As anticipated, 4th graders were more likely than middle schoolers to rate the rich as more competent in all domains. Consistent with a view that economic need leads to a realistic view of the limitations linked to poverty, youth from low-income families reported a slight advantage for the rich in sports, whereas youth from high-income families favored the poor. African American youth reported a stronger academic advantage for rich children than did White youth.

In the following, developmental differences in social class stereotypes are considered. Next, results regarding income and race differences in students' responses are discussed along with their implications for identity development. In closing, we provide suggestions for future research and policy implications of this work.

\section{Age Differences in Social Class Stereotypes}

Fourth graders in this sample reported beliefs that were more favorable toward the rich in all domains, whereas the reports of 6th and 8th graders differed across domains. These results are consistent with other research that has shown that as children enter adolescence, their views of the world are increasingly differentiated and complex (Chafel, 1995; Weinstein, 1958). Given their simplified social-cognitive knowledge and relatively limited experiences, younger children may rely on global/general attitudes toward groups. As they grow older, their understanding of economic inequality becomes more sophisticated, more complex, and more similar to adult beliefs (Chafel, 1997). It is likely that both maturational and experiential factors underlie these age differences. As children age, they are better able to encode, organize, and retrieve information, and they have more personal experiences on which to base their judgments of others.

Whereas 4th graders in our sample viewed the rich as more competent in all domains, middle schoolers reported an advantage for the rich in academics, egalitarian views in music, and an advantage for the poor in sports. Although 
it is not clear that there are consistent widespread beliefs about social class differences in music and sports abilities in our society, it is certainly the case that individuals from disadvantaged backgrounds are visible as successful athletes, musicians, and entertainers (e.g., Mike Tyson, Bo Jackson, Tupac Shakur, Keith Murray, Mary J. Blige, Shawn Carter (Jay-Z), Rusty Wallace, Marshall Mathers (Eminem), Wilma Rudolph, Althea Gibson, Deion Sanders, Vladamir Guerrero, Benito Santiago). The responses of older youth in our sample may reflect the idea presented in the popular media that athletic prowess and musical ability are 2 of the few possible avenues to success for economically disadvantaged individuals.

It should be noted that our measurement of stereotypes did not differentiate among specific sports or music genres. For example, youths may believe that poor individuals excel in certain sports (e.g., basketball) or music genres (e.g., rap), whereas other sports and music genres are dominated by the rich (e.g., golf, skiing, classical music).

\section{Race and Family Income Differences in Beliefs About the Rich and Poor}

African American and European American youths in our sample held stereotypes that favored the rich in academics, with Blacks reporting a stronger advantage for the rich. This finding, coupled with stereotype threat research, suggests that African American youth from disadvantaged backgrounds are at double risk. These youths must overcome negative social class stereotypes as well as negative race stereotypes about academic ability. Children's developing self-concept is primarily the product of interactions with others and of appraisals of themselves in comparison to others (Pajares and Schunk, 2002). Thus poor youth, especially ethnic minority youth who also face race stereotypes, are handicapped in a culture that perpetuates negative academic stereotypes about the poor. These stereotypes may lead poor youth to behave in selfhandicapping ways in order to minimize the negative implications of low performance (Aronson, 2002). For example, poor youth may not try to excel academically, or may devote relatively more energy to nonacademic activities. These youth need to be exposed to adults and societal messages that communicate that they are capable academically and are able to excel.

Both race and family income differences appeared in ratings of sports abilities, with European Americans and high-income youth favoring the poor, whereas African Americans and low-income youth were egalitarian. Regression analyses indicated that family income was a stronger force than race in driving group differences in beliefs. In contrast to more affluent students, students in our sample from low-income families reported egalitarian beliefs (or a very slight advantage for the rich) about sports abilities. This result is consistent with the view that personal experiences, rather than an in-group bias, are a stronger factor influencing these reports. Based on their personal experiences, these youth may have more realistic perceptions than their higher-income peers, recognizing that many poor individuals do not excel in athletics. Because of the visibility of successful athletes and musicians who came from indigent backgrounds, more affluent children reported that the poor have an advantage in these domains. In contrast, students from low-income backgrounds recognize that economic resources play a part in developing athletic performance (e.g., proper athletic attire, private coaches, transportation to practice). This recognition of the importance of access to economic resources, along with the societal view that athletics is an arena where the poor may excel, may have led to the egalitarian beliefs about the rich and poor in regard to sports reported by African Americans in our sample, who were overrepresented in our low-income group.

When asked to describe rich and poor individuals, low-income children in Leahy's (1981) study were more likely to mention the life chances and thoughts of the poor than were rich children. As Leahy's results indicate, poor children are probably more keenly aware than their affluent peers of both the short- and long-term consequences of poverty (e.g., poor nutrition, substandard health care, and poorer quality schools). Leahy (1981) found that poor children were more likely to take the perspective of the poor. Our results are consistent with the conclusion that it is the everyday experiences of disadvantaged youth rather than exposure to popular media that drive their beliefs about income-related differences in sports abilities.

\section{Future Directions for Research and Educational Policy}

One important avenue for future research is to determine whether and how children's and adolescents' beliefs about the rich and poor are related to their beliefs about their own abilities and identities. Adolescents' gender stereotypes about academic skills are related to their perceptions of their own skill in specific academic domains (Bornholt et al., 1994). However, social class membership is not as salient as gender, and some research has shown that children's perceptions of their families' economic standing are only weakly related to objective economic 
indices (Huston, 1994). For these reasons, children's endorsement of social class stereotypes may be unrelated to their self-perceptions.

Alternatively, youths who recognize that they are from disadvantaged backgrounds may come to believe that poor individuals are not as capable academically as rich individuals; however, these youths might attribute these group differences to situational factors (cf. Leahy, 1981). Thus, poor youth may not believe these stereotypes are a true representation of their own performance, or they may attribute poor academic performance to situational factors such as lowered teacher expectations. Such beliefs might result in a negative influence on performance (e.g., via social class stereotype threat, which has been found to negatively influence the performance of college students on tests of academic ability, Croizet and Claire, 1998), or may have a positive impact on motivation as individuals strive to show that they do not fit the stereotype (cf. Crocker and Major, 1989). Thus it remains for future research to determine whether negative stereotypes are detrimental and whether positive stereotypes are beneficial for poor and affluent children and adolescents.

Because of only a few high-income African American and low-income European American families in our sample, it was difficult to disentangle the influences of family income and race on social class stereotypes. Results of both the analyses of variance and regression analyses indicated that family income was a stronger factor driving students' beliefs than race in our data. To the extent to which stereotype threat is a significant factor for young adolescents, these results imply that youth from low-income backgrounds, regardless of race, are at risk for academic failure. Students from ethnic minority groups, however, must overcome 2 negative stereotypes and are therefore more vulnerable to the harmful effects of negative social class stereotypes. Future research should investigate the separate influences of these factors on social class stereotypes. Another important project for future research is longitudinal work that would examine change in beliefs from middle childhood through adolescence. Through such longitudinal designs, researchers could investigate the age at which social class stereotypes are first present and how these beliefs change over time, as well as identifying causal antecedents and consequences of beliefs.

The move toward celebration and affirmation of diversity in recent decades has successfully increased children's exposure to cultural diversity in many school settings, but has largely neglected economic diversity. Greater attention to economic diversity, including sensitivity training of educators could lead to greater awareness of the academic potential of all students (Croizet and
Claire, 1998). The relationship between the social and political climate of society and attitudes toward the poor is a 2-way street; thus an increase in social and political programs that address the issues and concerns of poor individuals is likely to result in a change in beliefs. Educational and political structures that support and encourage children and adolescents from disadvantaged backgrounds are essential to insure that all youths are valued in our society.

\section{ACKNOWLEDGMENTS}

This research was supported by NIMH 1 P50 MH52429 to Robert Cairns. Taniesha A. Woods was supported by an American Psychological Association Minority Fellowship. We wish to thank Laura Feagans, Patricia Johnson, Ryan Kinlaw, Julie Moore, Nikki Aikens, Crystal Barksdale, Tiffini Billingsley, Mayawa Obasaju, and Kimberly Taylor for assistance with data collection.

\section{REFERENCES}

Aronson, J. (2002). Stereotype threat: Contending and coping with unnerving expectations. In Aronson, J. (ed.), Improving Academic Achievement: Impact of Psychological Factors on Education. Academic Press, Amsterdam, pp. 281-299.

Bigler, R. S., Brown, C. S., and Markell, M. (2001). When groups are not created equal: Effects of group status on the formation of intergroup attitudes in children. Child Dev. 72: 1151-1162.

Bigler, R. S., and Liben, L. S. (1992). Cognitive mechanisms in children's gender stereotyping: Theoretical and educational implications of a cognitive-based intervention. Child Dev. 63: 1351-1363.

Bigler, R. S., and Liben, L. S. (1993). A cognitive-developmental approach to racial stereotyping and reconstructive memory in EuroAmerican children. Child Dev. 64: 1507-1518.

Bornholt, L. J., Goodnow, J. J., and Cooney, G. H. (1994). Influences of gender stereotypes on adolescents' perceptions of their own achievement. Am. Educ. Res. J. 31: 675-692.

Bullock, H. E. (1995). Class acts: Middle-class responses to the poor. In Lott, B., and Maluso, D. (eds.), Social Psychology of Interpersonal Discrimination. Guilford, New York, pp. 118-159.

Bullock, H. E. (1999). Attributions for poverty: A comparison of middleclass and welfare recipient attitudes. J. Appl. Soc. Psychol. 29: 2059-2082.

Bullock, H. E., Wyche, K. F., and Williams, W. R. (2001). Media images of the poor. J. Soc. Issues 57: 229-246.

Chafel, J. A. (1995). Children's conceptions of poverty. Adv. Early Educ. Day Care 7: 27-57.

Chafel, J. A. (1997). Societal images of poverty: Child and adult beliefs. Youth Soc. 28(4): 432-463.

Cozzarelli, C., Wilkinson, A. V., and Tagler, M. J. (2001). Attitudes toward the poor and attributions for poverty. J. Soc. Issues 57: 207-227.

Crocker, J., and Major, B. (1989). Social stigma and self-esteem: The self-protective properties of stigma. Psychol. Rev. 96: 608630.

Croizet, J.-C., and Claire, T. (1998). Extending the concept of stereotype threat to social class: The intellectual underperformance of students 
from low socioeconomic backgrounds. Pers. Psychol. Bull. 24(6): $588-594$.

Croizet, J.-C., Desert, M., Dutrevis, M., and Leyens, J. (2001). Stereotype threat, social class, gender, and academic under-achievement: When our reputation catches up to us and takes over. Soc. Psychol. Educ. 4: 295-310.

Freedman-Doan, C., Wigfield, A., Eccles, J. S., Blumenfeld, P., Arbreton, A., and Harold, R. D. (2000). What am I best at? Grade and gender differences in children's beliefs about ability improvement. J. Appl. Dev. Psychol. 21: 379-402.

Hamilton, D. L., Stroessner, S. J., and Driscoll, D. M. (1994). Social cognition and the study of stereotyping. In Devine, P. G., Hamilton, D. L., and Ostrom, T. M. (eds.), Social Cognition: Impact on Social Psychology. Academic Press, San Diego, CA, pp. 292-316.

Hunt, M. O. (1996). The individual, society, or both? A comparison of Black, Latino, and White beliefs about the causes of poverty. Soc. Forces 75: 293-322.

Huston, A. C. (1994). Children in poverty: Designing research to affect policy. Soc. Policy Rep. Soc. Res. Child Dev. 8(3): 1-12.

Leahy, R. L. (1981). The development of the conceptions of economic inequality. I. Descriptions and comparisons of rich and poor people. Child Dev. 52: 523-532.

Leahy, R. L. (1983). Development of the conception of economic inequality: II. Explanations, justifications, and concepts of social mobility and change. Dev. Psychol. 19(1): 111-125.

Lott, B. (2002). Cognitive and behavioral distancing from the poor. Am. Psychol. 57(2): 100-110.

Pajares, F., and Schunk, D. H. (2002). Self and self-belief in psychology and education: A historical perspective. In Aronson, J. (ed.), Improving Academic Achievement: Impact of Psychological Factors on Education. Academic Press, Amsterdam, pp. 5-21.

Ruble, T. L, Cohen, R., and Ruble, D. N. (1984). Sex stereotypes: Occupational barriers for women. Am. Behav. Sci. 27: 339-356.
Shapiro, I., Greenstein, R., and Primus, W. (2001, May 31). Pathbreaking CBO study shows dramatic increases in income disparities in 1980s and 1990s: An analysis of CBO data. Retrieved December 17, 2001, from the Center on Budget and Policy Priorities Web site: http://www.cbpp.org/5-31-01tax.htm.

Skafte, D. (1988). The effect of perceived wealth and poverty on adolescents' character judgments. J. Soc. Psychol. 129(1): 9399.

Snyder, M., and Stukas, A. A. (1999). Interpersonal processes: The interplay of cognitive, motivational, and behavioral activities in social interaction. Annu. Rev. Psychol. 50: 273303.

Steele, C. (1997). A threat in the air: How stereotypes shape the intellectual identities and performance of women and African Americans. Am. Psychol. 52: 613-629.

Stendler, C. (1949). Children of Brasstown. The University of Illinois Press, Urbana.

Tajfel, H. (1970). Experiments in intergroup discrimination. Sci. Am. 233: 96-102.

Tajfel, H., and Billig, M. (1974). Familiarity and categorization in intergroup behavior. J. Exp. Soc. Psychol. 10: 159-170.

Tiedemann, J. (2000). Parents' gender stereotypes and teachers' beliefs as predictors of children's concept of their mathematical ability in elementary school. J. Educ. Psychol. 92: 144-151.

U.S. Census Bureau. (2003). American Community Survey 2003 Data Profile [Data file]. http//www.census.gov/acs/www/Products/ Profiles/Single/2003/ACS/Tabular/010/01000US3.htm. Retrieved September 29, 2004.

Weinger, S. (1998). Poor children "know their place": Perceptions of poverty, class, and public messages. J. Sociol. Soc. Welfare 25: $100-118$.

Weinstein, E. (1958). Children's conceptions of occupational stratification. Sociol. Soc. Res. 42: 278-284. 


\section{COPYRIGHT INFORMATION}

TITLE: The Development of Stereotypes About the Rich and Poor: Age, Race, and Family Income Differences in Beliefs

SOURCE: J Youth Adolescavhlth Jron 34 no52102/12 O 200550652004

The magazine publisher is the copyright holder of this article and it is reproduced with permission. Further reproduction of this article in violation of the copyright is prohibited. To contact the publisher: http://www.springerlink.com/content/1573-6601/ 